\title{
Amiodarone for prevention of atrial fibrillation following esophagectomy
}

\section{ABSTRACT}

Objectives: Atrial fibrillation (AF) is a common complication after esophagectomy and is associated with symptoms, hemodynamic instability, prolonged hospital stay, and an increased incidence of mortality. Our objective was to determine the efficacy and safety of intravenous amiodarone for prophylaxis of postesophagectomy AF.

Methods: In this retrospective cohort study, 309 patients who underwent esophagectomy formed the initial cohort. Following propensity score-matching, 110 patients who received prophylactic amiodarone $43.75 \mathrm{mg} / \mathrm{hour}$ via continuous intravenous infusion over 96 hours (total dose, $4200 \mathrm{mg}$ ) were matched to a control group of patients who did not undergo amiodarone prophylaxis $(n=110)$. The propensity score was obtained using a multivariate logistic regression model with amiodarone as the variable and the following covariates: age, sex, surgical approach, history of neoadjuvant chemotherapy and/or radiation, chronic obstructive pulmonary disease, heart failure, cardiovascular disease, alcohol use ( $>7$ drinks/week), preadmission $\beta$-blockers discontinued during hospitalization, preoperative use of angiotensin-converting enzyme inhibitors or angiotensin receptor blockers, preoperative use of corticosteroids, postoperative use of angiotensinconverting enzyme inhibitors or angiotensin receptor blockers, postoperative use of corticosteroids, postoperative use of statins, and preoperative Charlson comorbidity index.

Results: The incidence of AF requiring treatment due to rapid ventricular rate and symptoms was lower in the amiodarone group (17 out of $110[15.5 \%]$ vs 32 out of 110 [29.1\%]; odds ratio, $0.45 ; 95 \%$ confidence interval, $0.23-0.86 ; P=.015$ ). There were no significant differences between the groups in median postoperative length of hospital stay, incidence of pulmonary complications, or mortality. The incidences of hypotension requiring treatment $(42.7 \%$ vs $21.8 \% ; P=.001)$, bradycardia $(8.2 \%$ vs $0.0 \% ; P=.002)$, and corrected QT interval prolongation $(10.9 \%$ vs $0.0 \% ; P \leq .0001)$ were significantly higher in the amiodarone group.

Conclusions: Prophylactic intravenous amiodarone is associated with a reduction in the incidence of AF following esophagectomy, but is not associated with shorter postoperative length of hospital stay. Intravenous amiodarone for prophylaxis of postesophagectomy AF is associated with hypotension, bradycardia, and corrected QT interval prolongation. (J Thorac Cardiovasc Surg 2019;158:301-10)

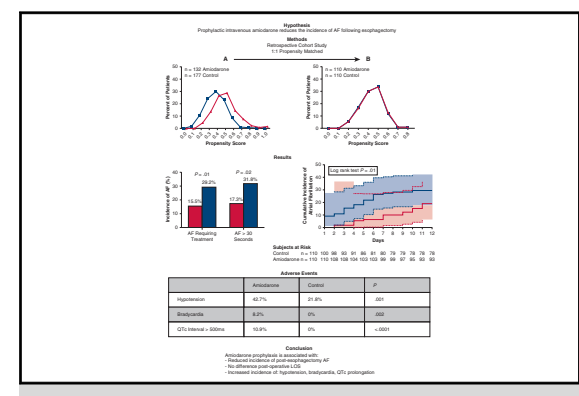

Amiodarone for prevention of postoperative AF: Hypothesis, design, results, and conclusions.

\section{Central Message}

Prophylactic IV amiodarone is associated with a reduction in AF following esophagectomy, but does not reduce length of hospital stay, and is associated with hypotension, bradycardia, and QT interval prolongation.

\section{Perspective}

Practice guidelines recommend intravenous (IV) amiodarone for prophylaxis of atrial fibrillation (AF) following esophagectomy, but data supporting this recommendation come from only one 1 randomized trial. This study provides additional data regarding the efficacy and, in particular, the safety of IV amiodarone for prevention of postesophagectomy $\mathrm{AF}$ in a larger patient cohort.

See Commentaries on pages 311 and 313.

\footnotetext{
From the a Department of Pharmacy Practice, College of Pharmacy, Purdue University, Indianapolis, Ind; ${ }^{b}$ Department of Medicine, School of Medicine, and ${ }^{\mathrm{d}}$ Department of Surgery, School of Medicine, Indiana University, Indianapolis, Ind; and ${ }^{\mathrm{c}}$ The Smith Center for Outcomes Research in Cardiology, Beth Israel Deaconess Medical Center, Harvard Medical School, Boston, Mass.

Presented at the 66th Annual Scientific Sessions of the American College of Cardiology, Washington, DC, March 19, 2017.
}

Received for publication July 9, 2018; revisions received Nov 30, 2018; accepted for publication Jan 19, 2019; available ahead of print March 8, 2019.

Address for reprints: James E. Tisdale, PharmD, College of Pharmacy, Purdue University, 640 Eskenazi Ave, Indianapolis, IN 46202 (E-mail: jtisdale@purdue.edu) 0022-5223/ $\$ 36.00$

Copyright (C) 2019 by The American Association for Thoracic Surgery https://doi.org/10.1016/j.jtcvs.2019.01.095 


$$
\begin{aligned}
& \text { Abbreviations and Acronyms } \\
& \begin{aligned}
\text { AF } & =\text { atrial fibrillation } \\
\text { ARDS } & =\text { acute respiratory distress syndrome } \\
\text { ICU } & =\text { intensive care unit } \\
\text { NNH } & =\text { number needed to harm } \\
\text { QTc } & =\text { corrected QT interval }
\end{aligned}
\end{aligned}
$$

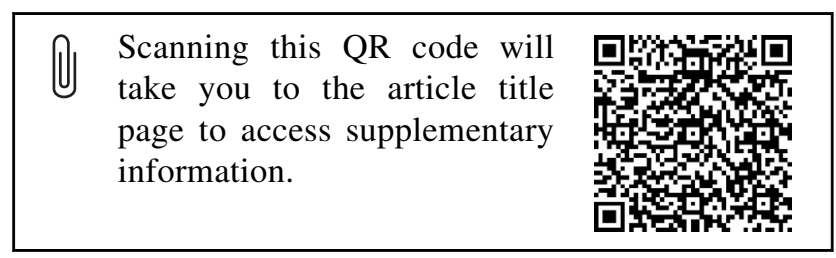

Atrial fibrillation (AF) occurs commonly postesophagectomy, with reported incidences ranging from $11 \%$ to $46 \%{ }^{1-15}$ Postesophagectomy AF is associated with symptoms, ${ }^{2}$ hemodynamic instability, ${ }^{2,3,5,16}$ prolonged duration of intensive care unit (ICU) and total hospital stay, ${ }^{2,5}$ and an increased incidence of mortality. ${ }^{2,3}$ In a small, randomized controlled trial, intravenous amiodarone, administered as a continuous infusion of $43.75 \mathrm{mg} /$ hour for 96 hours (total dose, $4200 \mathrm{mg}$ ), significantly reduced the incidence of $\mathrm{AF}$ after esophagectomy. ${ }^{6}$ The incidence of adverse effects in the amiodarone group was not significantly different than that in the control group. ${ }^{6}$ Primarily as a result of that study, amiodarone is recommended in practice guidelines for prophylaxis of postesophagectomy AF. ${ }^{17,18}$ However, the clinical study supporting these recommendations enrolled a relatively small sample $(\mathrm{n}=40$ in the amiodarone group and $n=40$ in the control group), which may have been too small to detect differences between the amiodarone and control groups in duration of postoperative hospital stay or adverse effects. To date, this is the only published study of AF prophylaxis in a dedicated esophagectomy population. Therefore, there is a paucity of data regarding the efficacy and safety of AF prophylaxis strategies in this surgical population. The objective of this study was to test the hypothesis that intravenous amiodarone is effective and safe for prophylaxis of AF following esophagectomy in a larger patient cohort.

\section{MATERIALS AND METHODS Patients}

This retrospective, propensity score-matched cohort study was conducted at Indiana University Health University Hospital, a 270-bed tertiary care institution in Indianapolis, Ind. Electronic medical records of 309 consecutive patients who underwent esophagectomy from January 2009 to December 2015 were reviewed. All patients aged 18 years or older who underwent esophagectomy via an open or minimally invasive approach during this time period were eligible for inclusion. Patients with a history of AF were excluded. This study was approved (exempt status) by the Institutional Review Board at Indiana University; the requirement for written informed consent was waived.

Patients were divided into 2 groups: those who received prophylactic intravenous amiodarone and a control group of patients who did not, which was matched to the amiodarone group at a 1:1 ratio using propensity score matching. The decision to administer amiodarone for postoperative AF prophylaxis was made by each individual surgeon. Amiodarone was administered by continuous intravenous infusion, initiated at the time of induction of anesthesia, at $43.75 \mathrm{mg} /$ hour for 96 hours (total dose, $4200 \mathrm{mg}$ ). ${ }^{6,17}$ All patients underwent continuous telemetry monitoring, equipped with a triggered alarm and recording systems for abnormal rhythms. Patients who developed AF were managed by critical care attending physicians, cardiology consultants, surgical resident physicians, or surgical attending physicians during routine postoperative care with rate control and rhythm conversion strategies, including additional amiodarone therapy, as deemed clinically appropriate. Electronic medical records were reviewed for demographic characteristics, concomitant disease states and medications, laboratory values, surgery type, occurrence of AF, and incidence and nature of postoperative adverse events and complications.

\section{Outcome Measures}

Primary outcome measures were incidence of $\mathrm{AF}$ requiring treatment due to rapid ventricular rate and symptoms including shortness of breath, dizziness, fatigue, or hemodynamic compromise ${ }^{18,19}$ and incidence of any $\mathrm{AF}$ (treated or untreated) lasting longer than 30 seconds. ${ }^{18}$ Secondary outcome measures were duration of postoperative hospital stay, incidence of adverse effects, and in-hospital mortality. Pulmonary adverse effects were defined as pneumonia, unplanned reintubation $\geq 24$ hours after extubation, and/or acute respiratory distress syndrome (ARDS) (Berlin defini$\operatorname{tion}^{20}$ ). Hypotension was defined as that requiring treatment with fluid and/ or vasopressors; bradycardia was defined as heart rate $<50 \mathrm{bpm}$ or requiring treatment; heart rate-corrected QT $(\mathrm{QTc})$ interval prolongation was defined as Bazett's-corrected QT interval $>500 \mathrm{~ms}$.

Some patients who developed postoperative AF despite receiving intravenous amiodarone prophylaxis continued to receive intravenous amiodarone for management of $\mathrm{AF}$, and therefore received a higher cumulative amiodarone dose than those patients who received only the cumulative prophylaxis dose $(4200 \mathrm{mg})$. Consequently, in an exploratory, hypothesisgenerating analysis, we compared the incidence of adverse effects associated with intravenous amiodarone in patients who received a cumulative dose $>4200 \mathrm{mg}$ with those who received a cumulative intravenous amiodarone dose $\leq 4200 \mathrm{mg}$.

\section{Data Analysis}

Normality of continuous data was determined using the KolmogorovSmirnov test. Continuous, normally distributed data were analyzed with Student unpaired 2-tailed $t$ test. Continuous, nonnormally distributed data were analyzed with the Wilcoxon rank-sum test. Noncontinuous data were analyzed with the $\chi^{2}$ or Fisher exact test as appropriate. The primary analysis was intention-to-treat; patients in the control group who developed AF and were subsequently treated with amiodarone were maintained in the control group for analysis of safety data. Kaplan-Meier analysis was used to compare cumulative incidence of AF. Odds ratios (ORs) and $95 \%$ confidence intervals (CIs) were calculated.

To control for potential confounders, propensity score matching was performed using a 1:1 greedy nearest neighbor algorithm approach to form pairs of amiodarone prophylaxis patients versus controls with \pm 0.01 caliper with no replacement for adjustment of significantly different patient characteristics. The propensity score was obtained using a multivariate logistic regression model with amiodarone as the variable and the following covariates: age (as a continuous variable), sex, surgical approach (open vs minimally invasive), history of neoadjuvant chemotherapy and/or 
radiation, chronic obstructive pulmonary disease, heart failure, cardiovascular disease (documented history of ischemic heart disease), alcohol use (defined as $>7$ drinks per week), preadmission $\beta$-blockers discontinued during hospitalization, preoperative use of angiotensin-converting enzyme inhibitors or angiotensin receptor blockers, preoperative use of corticosteroids, postoperative use of angiotensin-converting enzyme inhibitors or angiotensin receptor blockers, postoperative use of corticosteroids, postoperative use of statins, and preoperative Charlson comorbidity index. ${ }^{21} \mathrm{Co}-$ variates were selected on the basis of being prominent and important risk factors for postesophagectomy $\mathrm{AF}^{22,23}$ and/or because they were associated with standardized mean differences $>0.2 \%$ before propensity score matching. Statistical analyses were performed using the statistical software SAS version 9.4 (SAS Institute Inc, Cary, NC).

\section{RESULTS}

\section{Study Population}

The initial cohort comprised 309 consecutive patients who underwent esophagectomy. Of these, 132 received intravenous amiodarone for AF prophylaxis, and $177 \mathrm{did}$ not undergo AF prophylaxis with amiodarone (control cohort).

\section{Unmatched Population}

The baseline characteristics of the 2 groups before propensity score-matching are reported in Table 1 . The amiodarone prophylaxis group was older and had a lower proportion of men.

\section{Matched Population}

The propensity score-matched algorithm successfully matched 110 patients who underwent esophagectomy and who received amiodarone prophylaxis for postoperative AF with 110 patients who underwent esophagectomy but who did not undergo amiodarone prophylaxis for

TABLE 1. Distribution of patient characteristics before propensity score-matching in the amiodarone and control groups

\begin{tabular}{|c|c|c|c|c|}
\hline Characteristic & $\begin{array}{c}\text { Amiodarone } \\
(\mathrm{n}=132)\end{array}$ & $\begin{array}{c}\text { Control } \\
(\mathbf{n}=177)\end{array}$ & $\begin{array}{l}\text { Standardized mean } \\
\text { difference }(\%)\end{array}$ & $P$ value \\
\hline Age $(y)$ & $68 \pm 11$ & $64 \pm 11$ & 0.98 & .004 \\
\hline Male sex & $92(70.0)$ & $139(78.5)$ & 0.12 & .08 \\
\hline White race & $114(86.4)$ & $159(89.8)$ & 0.04 & .35 \\
\hline Current tobacco use & $52(39.4)$ & $68(38.4)$ & -0.03 & .86 \\
\hline Alcohol use $>7$ drinks/wk & $18(13.6)$ & $32(18.1)$ & 0.29 & .29 \\
\hline Neoadjuvant chemotherapy and/or radiation & $42(31.8)$ & $50(28.2)$ & 0.12 & .50 \\
\hline Minimally invasive surgical approach* & $37(28.0)$ & $38(21.5)$ & 0.27 & .18 \\
\hline \multicolumn{5}{|l|}{ Comorbid conditions } \\
\hline Charlson comorbidity index & $5.1 \pm 1.6$ & $4.9 \pm 1.7$ & 0.13 & .30 \\
\hline Hypertension & $58(43.9)$ & $85(48.0)$ & -0.09 & .48 \\
\hline Cardiovascular disease $\dagger$ & $45(34.1)$ & $62(35.0)$ & 0.03 & .86 \\
\hline Heart failure & $9(6.8)$ & $10(5.6)$ & -0.21 & .67 \\
\hline Hyperlipidemia & $34(25.8)$ & $48(27.1)$ & 0.05 & .79 \\
\hline Type 1 or 2 diabetes mellitus & $34(25.8)$ & $50(28.2)$ & -0.09 & .24 \\
\hline COPD & $32(24.2)$ & $48(27.1)$ & 0.12 & .57 \\
\hline \multicolumn{5}{|l|}{ Preadmission medications } \\
\hline$\beta$-blockers & $21(15.9)$ & 30 (16.9) & -0.06 & .81 \\
\hline Calcium channel blockers $\ddagger$ & $19(14.4)$ & $30(16.9)$ & -0.16 & .54 \\
\hline Statins & $31(23.5)$ & $47(26.6)$ & -0.12 & .54 \\
\hline ACE inhibitors/ARBs & $15(11.4)$ & $25(14.1)$ & -0.22 & .46 \\
\hline Loop diuretics & $14(10.6)$ & $20(11.3)$ & -0.07 & .85 \\
\hline Corticosteroids & $13(9.8)$ & $14(7.9)$ & 0.23 & .55 \\
\hline Preadmission $\beta$-blockers discontinued during hospitalization & $3(2.3)$ & $2(1.1)$ & 0.96 & .43 \\
\hline \multicolumn{5}{|l|}{ Medications administered postoperatively during hospitalization } \\
\hline$\beta$-blockers & $65(49.2)$ & $98(55.4)$ & -0.12 & .29 \\
\hline Calcium channel blockers $\ddagger$ & $7(5.3)$ & $11(6.2)$ & -0.17 & .74 \\
\hline Statins & $12(9.1)$ & $14(7.9)$ & 0.15 & .71 \\
\hline ACE inhibitors/ARBs & $5(3.8)$ & $5(2.8)$ & 0.36 & 64 \\
\hline Loop diuretics & $65(49.2)$ & $85(48.0)$ & 0.02 & .83 \\
\hline Corticosteroids & $11(8.3)$ & $10(5.6)$ & 0.41 & .35 \\
\hline
\end{tabular}

Values are presented as mean \pm standard deviation for continuous variables or $\mathrm{n}(\%)$. COPD, Chronic obstructive pulmonary disease; $A C E$, angiotensin-converting enzyme; $A R B s$, angiotensin receptor blockers. *Patients who underwent esophagectomy for malignancy also underwent en bloc periesophageal and celiac lymph node dissection. $\dagger$ Defined as documented ischemic heart disease (does not include heart failure). $\ddagger$ Diltiazem or verapamil. 
postoperative AF. The baseline characteristics for the matched groups are presented in Table 2. Following propensity score-matching, all standardized mean differences are small. Mirror histograms for the propensity scores matches are provided in Figure E1.

\section{Incidence of $\mathbf{A F}$}

$\mathrm{AF}$ requiring treatment occurred in 49 out of 220 patients $(22.3 \%)$. The incidence of postesophagectomy $\mathrm{AF}$ requiring treatment was significantly lower in the amiodarone prophylaxis group (Figure 1). The OR for AF requiring treatment in amiodarone prophylaxis patients was 0.45 (95\% CI, 0.23-0.86), corresponding to a $55 \%$ relative reduction in the odds of $\mathrm{AF}$ associated with amiodarone prophylaxis. The absolute reduction in risk of $\mathrm{AF}$ requiring treatment was $13.6 \%$ (95\% CI, $2.8 \%-24.4 \%)$. The number needed to treat with amiodarone to prevent one episode of $\mathrm{AF}$ requiring treatment was 7.4 (95\% CI 4.1-35.9). Of 17 patients in the amiodarone prophylaxis group who developed AF requiring treatment, 3 patients $(17.6 \%)$ were discharged from the hospital in AF, compared with 3 out of 32 $(9.4 \%)$ in the control group $(P=.50)$. The cumulative incidence of $\mathrm{AF}$ requiring treatment over time is displayed in Figure 2.

AF lasting longer than 30 seconds (treated or untreated) occurred in 54 out of 220 patients $(24.5 \%)$. The incidence of postesophagectomy AF lasting longer than 30 seconds was significantly lower in the amiodarone group (Figure 1). The OR for AF lasting longer than 30 seconds in amiodarone prophylaxis patients was $0.45(95 \% \mathrm{CI}$, $0.24-0.85$ ), corresponding to a $55 \%$ relative reduction in the odds of AF associated with amiodarone prophylaxis.

TABLE 2. Distribution of patient characteristics after propensity score-matching in the amiodarone and control groups

\begin{tabular}{|c|c|c|c|c|}
\hline Characteristic & $\begin{array}{c}\text { Amiodarone } \\
(\mathbf{n}=\mathbf{1 1 0})\end{array}$ & $\begin{array}{c}\text { Control } \\
(n=110)\end{array}$ & $\begin{array}{c}\text { Standardized mean } \\
\text { difference }(\%)\end{array}$ & $P$ value \\
\hline Age $(y)$ & $66 \pm 10$ & $66 \pm 10$ & 0.00 & .77 \\
\hline Male sex & $81(73.6)$ & $78(70.9)$ & 0.04 & .65 \\
\hline White race & $98(89.1)$ & $95(86.4)$ & 0.03 & .54 \\
\hline Current tobacco use & $44(40.0)$ & $43(39.1)$ & 0.02 & .89 \\
\hline Alcohol use $>7$ drinks/wk & $15(13.6)$ & $17(15.5)$ & -0.14 & .70 \\
\hline Neoadjuvant chemotherapy and/or radiation & $36(32.7)^{*}$ & $32(29.1)^{*}$ & 0.12 & .56 \\
\hline Minimally invasive surgical approach $\dagger$ & $27(24.5)$ & $26(23.6)$ & 0.04 & .88 \\
\hline \multicolumn{5}{|l|}{ Comorbid conditions } \\
\hline Charlson comorbidity index & $5.0(1.5)$ & $5.0(1.6)$ & 0.00 & .97 \\
\hline Hypertension & $50(45.5)$ & $54(49.1)$ & -0.08 & .59 \\
\hline Cardiovascular disease $\ddagger$ & $36(32.7)$ & $39(35.5)$ & -0.08 & .67 \\
\hline Heart failure & $6(5.5)$ & $7(6.4)$ & -0.17 & .78 \\
\hline Hyperlipidemia & $29(26.4)$ & $30(27.3)$ & -0.03 & .88 \\
\hline Type 1 or 2 diabetes mellitus & $28(25.5)$ & $32(29.1)$ & -0.13 & .54 \\
\hline COPD & $27(24.5)$ & $28(25.5)$ & -0.04 & .88 \\
\hline \multicolumn{5}{|l|}{ Preadmission medications } \\
\hline$\beta$-blockers & $16(14.5)$ & $17(15.5)$ & -0.07 & .85 \\
\hline Calcium channel blockers $\S$ & $16(14.5)$ & $14(12.7)$ & 0.14 & .69 \\
\hline Statins & $28(25.5)$ & $32(29.1)$ & -0.13 & .54 \\
\hline ACE inhibitors/ARBs & $12(10.9)$ & $14(12.7)$ & -0.16 & .75 \\
\hline Loop diuretics & $10(9.1)$ & $12(10.9)$ & -0.19 & .65 \\
\hline Corticosteroids & $8(7.3)$ & $8(7.3)$ & 0.00 & $>.99$ \\
\hline Preadmission $\beta$-blockers discontinued during hospitalization & $2(1.8)$ & $2(1.8)$ & 0.00 & $>.99$ \\
\hline \multicolumn{5}{|l|}{ Medications administered postoperatively during hospitalization } \\
\hline$\beta$-blockers & $63(57.3)$ & $64(58.2)$ & -0.02 & .89 \\
\hline Calcium channel blockers $\ddagger$ & $5(4.5)$ & $5(4.5)$ & 0.00 & $>.99$ \\
\hline Statins & $11(10.0)$ & $11(10.0)$ & 0.00 & $>.99$ \\
\hline ACE inhibitors/ARBs & $3(2.7)$ & $3(2.7)$ & 0.00 & $>.99$ \\
\hline Loop diuretics & $54(49.1)$ & $51(46.4)$ & 0.06 & 69 \\
\hline Corticosteroids & $5(4.5)$ & $5(4.5)$ & 0.00 & $>.99$ \\
\hline
\end{tabular}

Values are presented as mean \pm standard deviation for continuous variables or $\mathrm{n}(\%) . C O P D$, Chronic obstructive pulmonary disease; $A C E$, angiotensin-converting enzyme; $A R B s$, angiotensin receptor blockers. *Two patients had chemotherapy only. †Patients who underwent esophagectomy for malignancy also underwent en bloc periesophageal and celiac lymph node dissection. ‡๋efined as documented ischemic heart disease (does not include heart failure). §Diltiazem or verapamil. 


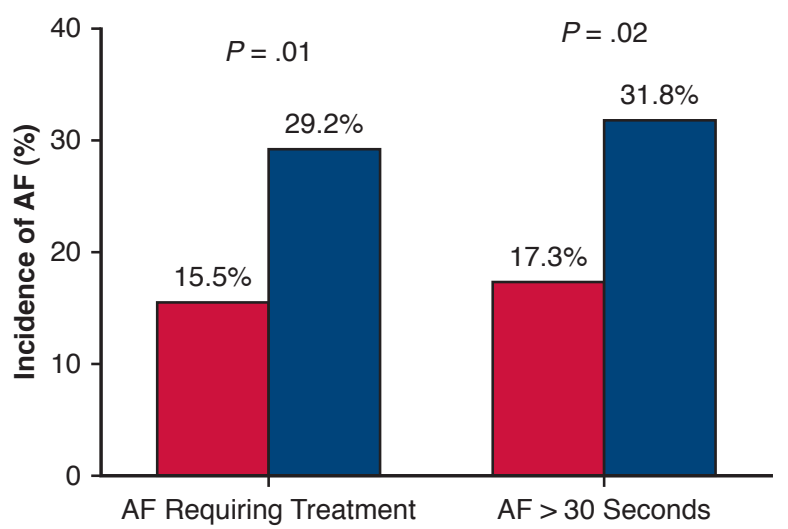

FIGURE 1. Incidence of atrial fibrillation $(A F)$ in the amiodarone prophylaxis (red) and control (blue) groups.

The absolute reduction in risk of $\mathrm{AF}$ lasting longer than 30 seconds was $14.5 \%$ (95\% CI, 3.3\%-25.6\%). The number needed to treat with intravenous amiodarone to prevent 1 episode of AF lasting longer than 30 seconds was 6.9 (95\% CI, 3.9-30.0).

\section{Duration of Postoperative Hospital Stay}

The mean postoperative duration of hospital stay in the overall study population $(\mathrm{n}=220)$ was $14 \pm 9$ days with a median of 11 days (interquartile range [IQR], 9-15 days). The median duration of postoperative hospital stay was not significantly different among patients who developed $\mathrm{AF}$ requiring treatment compared with those who did not (11 days; IQR, 9-15 days vs 11 days; IQR, 9-17 days; $P=.45$ ). There was no significant difference in median duration of postoperative hospital stay in the amiodarone prophylaxis group compared with the control group (11 days; IQR, 9-18 days vs 10 days; IQR, 9-13 days; $P=.26)$.

\section{Treatment of Postesophagectomy AF}

Management of 49 patients who developed AF requiring treatment following esophagectomy is presented in Table 3. There were no significant differences between the amiodarone prophylaxis and control groups in the proportion of patients who underwent treatment with intravenous diltiazem, esmolol, and/or direct current cardioversion. Most patients $(84 \%)$ who developed AF were treated with intravenous amiodarone, including 17 patients $(100 \%)$ who developed AF after having received amiodarone $4200 \mathrm{mg}$ for AF prophylaxis. Among patients who received intravenous amiodarone for treatment of postoperative AF, there was a significant difference between the amiodarone prophylaxis and control groups in the median duration of intravenous amiodarone infusion administered for purposes of AF treatment (5 days; IQR, 3-8 days vs 6.5 days; IQR, 4-10 days, respectively; $P=.03$ ). Among patients who developed $\mathrm{AF}$ in the amiodarone prophylaxis and control groups, there was no significant difference in the overall incidence of conversion to normal sinus rhythm within 24 hours ( 8 out of 17 [47.1\%] vs 12 out of $32[37.5 \%] ; P=.42)$. There was no significant difference in the incidence of conversion to normal sinus rhythm within 24 hours between patients who received amiodarone for management of postesophagectomy AF and those who received other treatments (16 out of $41[39.0 \%]$ vs 4 out of $8[50.0 \%] ; P=.70)$. There was no significant difference in the proportion of patients

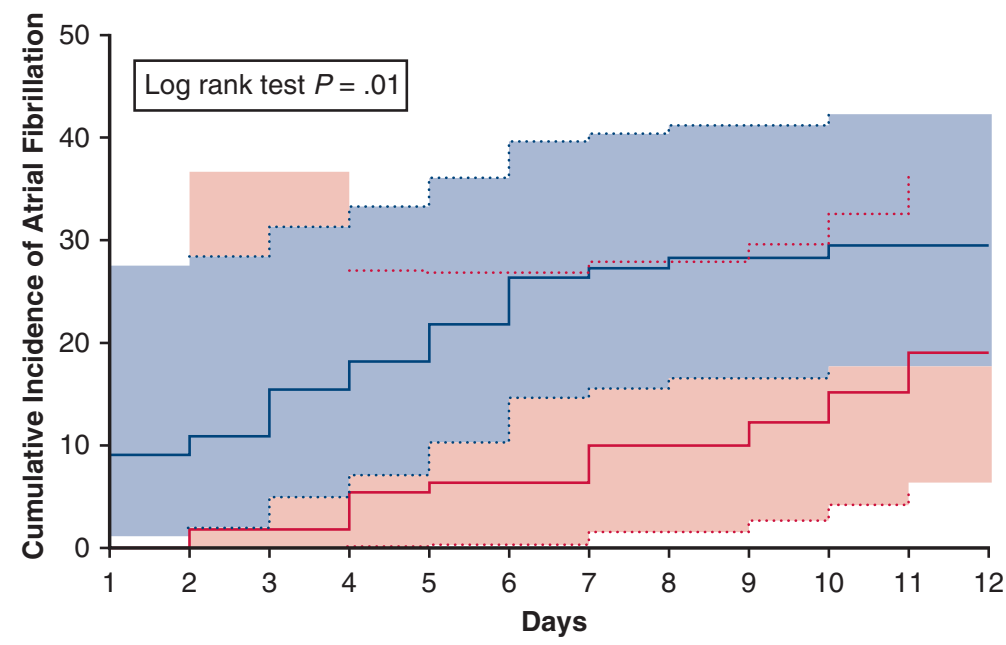

Subjects at Risk

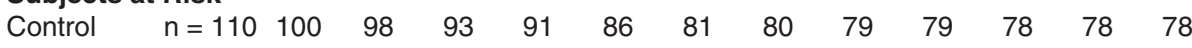

\begin{tabular}{|c|}
\hline$a_{n} n-110-1$ \\
\hline darone $n=110110$ \\
\hline
\end{tabular}

FIGURE 2. Kaplan-Meier cumulative incidence of atrial fibrillation requiring treatment. Confidence limits for amiodarone (red) and control group (blue) indicated by shading. 
TABLE 3. Management of postesophagectomy atrial fibrillation

\begin{tabular}{|c|c|c|c|}
\hline Variable & Amiodarone prophylaxis $(\mathrm{n}=17)$ & Control $(\mathbf{n}=32)$ & $P$ value \\
\hline Treated with intravenous amiodarone & $17(100.0)$ & $24(75.0)$ & .04 \\
\hline Cumulative amiodarone dose including prophylaxis dose $(\mathrm{mg})^{*}$ & $5720(5202-6190)$ & $3460(2700-5400)$ & $<.0001$ \\
\hline $\begin{array}{l}\text { Patients who received a cumulative amiodarone dose beyond the } \\
\text { prophylactic dose* }\end{array}$ & $10(58.8)$ & $16(50.0)$ & .56 \\
\hline Amiodarone dose in excess of prophylaxis dose $(\mathrm{mg})^{*}$ & $2080(1120-3225)(\mathrm{n}=10)$ & $2000(900-2200)(n=16)$ & .90 \\
\hline Direct current cardioversion & $1(5.9)$ & $3(9.4)$ & $>.99$ \\
\hline Intravenous diltiazem & $5(29.4)$ & $6(18.8)$ & .48 \\
\hline Intravenous esmolol & $2(11.8)$ & $3(9.4)$ & $>.99$ \\
\hline
\end{tabular}

Values are presented as $\mathrm{n}(\%)$ or median (interquartile range). *Prophylaxis dose was $4200 \mathrm{mg}$ amiodarone by continuous intravenous infusion over 96 hours.

discharged from the hospital in AF between those in whom AF was treated with amiodarone (5 out of $41[12.2 \%])$ versus those who received other therapies ( 1 out of 8 $[12.5 \%])(P>.99)$. Five of 6 patients who were discharged from the hospital in $\mathrm{AF}$ were receiving anticoagulation therapy (all 5 from the amiodarone-treated group).

\section{Postoperative Adverse Events, Morbidity, and Mortality}

The incidence of adverse events in the amiodarone prophylaxis and control groups is presented in Table 4. There were no significant differences between the groups in the incidence of pulmonary complications. Hypotension requiring treatment with fluids or vasopressors, bradycardia and QTc interval prolongation occurred more frequently in the amiodarone prophylaxis group; no patients experienced torsades de pointes. The number needed to harm $(\mathrm{NNH})$ due to amiodarone-associated hypotension requiring treatment was 4.8 (95\% CI, 3.0-11.3). The $\mathrm{NNH}$ resulting from amiodarone-associated bradycardia was 12.2 (95\% CI,

TABLE 4. Postoperative adverse events and morbidity

\begin{tabular}{lccc}
\hline \multicolumn{1}{c}{ Adverse event } & $\begin{array}{c}\text { Amiodarone } \\
\text { prophylaxis } \\
(\mathbf{n}=\mathbf{1 1 0})\end{array}$ & $\begin{array}{c}\text { Control } \\
(\mathbf{n}=\mathbf{1 1 0})^{*}\end{array}$ & $\boldsymbol{P}$ value \\
\hline Hypotension $\dagger$ & $47(42.7)$ & $24(21.8)$ & .001 \\
Bradycardia $\ddagger$ & $9(8.2)$ & $0(0.0)$ & .002 \\
Corrected QT interval & $12(10.9)$ & $0(0.0)$ & $<.0001$ \\
$\quad>500 \mathrm{~ms}$ & & & \\
Pulmonary complications & $1(0.9)$ & $1(0.9)$ & $>.99$ \\
$\quad$ ARDS & $13(11.8)$ & $11(10.0)$ & .67 \\
$\quad \begin{array}{l}\text { Pneumonia } \\
\text { Unplanned reintubation }\end{array}$ & $12(10.9)$ & $11(10.0)$ & .83 \\
$\quad>24$ h after extubation & & & \\
Death & $2(1.8)$ & $2(1.8)$ & $>.99$ \\
\hline
\end{tabular}

Values are presented as $\mathrm{n}(\%)$. ARDS, Acute respiratory distress syndrome. *Twentyfour patients in this group received intravenous amiodarone for treatment of postesophagectomy atrial fibrillation. $\dagger$ Hypotension requiring treatment with fluid bolus or vasopressors. $\ddagger$ Bradycardia was defined as heart rate $<50 \mathrm{bpm}$ and/or requiring treatment.
7.5-32.7), while the NNH due to amiodarone-associated QTc interval prolongation was 9.2 (95\% CI, 6.0-19.7). Amiodarone was discontinued in 9 patients $(7.8 \%)$ in the prophylaxis group, 5 of whom developed AF, were initially continued amiodarone on amiodarone for $\mathrm{AF}$ treatment, and then were treated with alternate therapy, and 4 of whom developed hypotension. The incidence of in-hospital mortality between the groups was not significantly different. There were 4 postoperative deaths: 3 patients died of pneumonia-associated sepsis (hospital days 18, 22, and 53) and 1 patient died of sepsis related to an anastamosis leak on hospital day 6 .

Ten patients in the amiodarone prophylaxis group who developed AF received additional amiodarone beyond the recommended prophylaxis dose $(4200 \mathrm{mg})$ for treatment of $\mathrm{AF}^{6,17}$ Of 32 patients in the control group who developed $\mathrm{AF}, 24$ received amiodarone for $\mathrm{AF}$ management (Table 3). Many patients in the control group received cumulative amiodarone doses $>4200 \mathrm{mg}$. Among all patients who received amiodarone for AF prophylaxis and/or treatment $(\mathrm{n}=134 ; 110$ in the amiodarone prophylaxis group and 24 in the control group who subsequently received amiodarone for AF treatment), the incidence of specific amiodarone-associated adverse events was significantly higher in patients who received cumulative amiodarone doses $>4200 \mathrm{mg}$ than in those who received $\leq 4200 \mathrm{mg}$ (Table 5). The incidence of hypotension requiring treatment was significantly higher in the amiodarone $>4200 \mathrm{mg}$ group. However, $76.9 \%$ of patients in the $>4200 \mathrm{mg}$ group developed AF, compared with 51 out of 116 patients $(44.0 \%)$ in the $\leq 4200 \mathrm{mg}$ group $(P=.004)$; this may have contributed to a greater incidence of hypotension. The incidences of amiodarone-associated bradycardia and QTc interval prolongation were significantly higher in patients who received a cumulative amiodarone dose $>4200 \mathrm{mg}$.

The incidence of ARDS in patients who received cumulative amiodarone dose $>4200 \mathrm{mg}$ compared with those that received $\leq 4200 \mathrm{mg}$ was not significantly different. The patient in the amiodarone dose $>4200 \mathrm{mg}$ group who 
TABLE 5. Amiodarone-associated adverse events among patients who received a cumulative amiodarone dose $>4200 \mathrm{mg}$ compared with those who received $\leq 4200 \mathrm{mg}$

\begin{tabular}{|c|c|c|c|}
\hline Adverse event & $\begin{array}{c}\text { Amiodarone } \\
>4200 \mathrm{mg} \\
(\mathrm{n}=26)^{*}\end{array}$ & $\begin{array}{c}\text { Amiodarone } \\
\leq \mathbf{4 2 0 0} \mathrm{mg} \\
(\mathrm{n}=\mathbf{1 0 8}) \dagger\end{array}$ & $P$ value \\
\hline Hypotension $\ddagger$ & $20(76.9)$ & $34(31.5)$ & $<.001$ \\
\hline Bradycardia $\S$ & $5(19.2)$ & $4(3.7)$ & .01 \\
\hline $\begin{array}{l}\text { Corrected QT } \\
\quad \text { interval }>500 \mathrm{~ms}\end{array}$ & $10(38.5)$ & $2(1.9)$ & $<.001$ \\
\hline \multicolumn{4}{|l|}{ Pulmonary complications } \\
\hline ARDS & $1(3.8)$ & $1(0.9)$ & .33 \\
\hline Pneumonia & $6(23.1)$ & $14(13.0)$ & .19 \\
\hline $\begin{array}{l}\text { Unplanned reintubation } \\
>24 \mathrm{~h} \text { after extubation }\end{array}$ & $6(23.1)$ & $15(13.9)$ & .25 \\
\hline Death from any cause & $2(7.7)$ & $2(1.9)$ & .15 \\
\hline
\end{tabular}

Values are presented as $\mathrm{n}(\%)$. ARDS, Acute respiratory distress syndrome. *Ten patients who received amiodarone prophylaxis for atrial fibrillation and who continued taking amiodarone for management of postesophagectomy atrial fibrillation plus 16 patients in the control group who developed postesophagectomy atrial fibrillation and were initiated on intravenous amiodarone for treatment. $\dagger$ Ninety-three patients who received intravenous amiodarone at the prophylactic cumulative dose $\leq 4200 \mathrm{mg}$ plus 7 patients who developed atrial fibrillation while receiving prophylactic amiodarone but did not exceed dose of $4200 \mathrm{mg}$ plus 8 patients in the control group who developed postesophagectomy atrial fibrillation and were treated with intravenous amiodarone whose cumulative amiodarone dose did not exceed $4200 \mathrm{mg}$. $\ddagger$ Hypotension was defined as requiring treatment with fluid bolus or vasopressors. $\S$ Bradycardia was defined heart rate $<50 \mathrm{bpm}$ and/or requiring treatment.

developed ARDS received a very high cumulative dose $(8559 \mathrm{mg}$ ), and had multiple comorbidities, including preoperative chemotherapy and radiation, and a history of smoking, COPD, and heart disease. He was mechanically ventilated at inspired oxygen fraction $50 \%$, underwent tracheostomy on postoperative day 6 , and was weaned off ventilation and sent to a rehabilitation facility.

\section{DISCUSSION}

In this study, amiodarone prophylaxis was associated with a significant reduction in the incidence of postesophagectomy AF. The incidence of AF in the amiodarone prophylaxis group was similar to that in our previously published small, randomized, controlled clinical trial ${ }^{6}$; however, the AF incidence in the control group was lower than in the randomized study, which translated into smaller unadjusted relative risk reductions in real-world practice. Reasons for the lower incidence of AF in the control group in this analysis compared with that in the randomized trial may include differences in patient population in the control group of this real-world study: nearly 3 times the incidence of administration of postoperative $\beta$-blockers and lower incidence of preoperative discontinuation of $\beta$-blockers, lower incidence of preoperative chemotherapy and radiation, and higher incidence of preoperative use of statins and calcium channel blockers. However, despite these differences, the incidence of postesophagectomy AF was significantly lower in patients who underwent amiodarone prophylaxis than in those who did not.

Although prophylactic amiodarone was associated with a reduced incidence of postesophagectomy AF, this did not translate into a reduction in the total duration of postoperative hospital stay. Although one meta-analysis of studies of AF prophylaxis following cardiac surgery found significant reductions in length of hospital stay associated with amiodarone and other prophylactic strategies, ${ }^{24}$ the majority of studies of AF prophylaxis following thoracic surgery, whether coronary artery bypass grafting, ${ }^{19,24}$ heart valve surgery, ${ }^{19,25}$ pulmonary resection, ${ }^{26,27}$ or esophagectomy ${ }^{6}$ have not reported significant reductions in length of hospital stay associated with decreases in the incidence in postoperative AF. The postoperative lengths of hospital stay in our study were somewhat longer than those reported by other centers. The reason for this is that, during the time period of the study, our practice was to obtain a contrast esophagram on postoperative day 7 with a 3-day diet progression before discharge. More recently our practice has changed to obtain the contrast esophagram on postoperative days 4 to 6 , which has resulted in shorter durations of hospital stay than are reflected in this study.

Although amiodarone is effective for prophylaxis of postesophagectomy $\mathrm{AF}$, it was also associated with hypotension, bradycardia, and QTc interval prolongation. A $10 \%$ incidence of QTc interval prolongation associated with intravenous amiodarone is of concern, because QTc interval $>500 \mathrm{~ms}$ is associated with an increased risk of the lifethreatening arrhythmia torsades de pointes. ${ }^{28}$ Therefore, monitoring of the QTc interval with 12-lead electrocardiograms and/or continuous electrocardiogram monitoring is warranted in patients receiving amiodarone prophylaxis (or treatment) of postesophagectomy AF, and amiodarone should be discontinued in patients with QTc interval $>500 \mathrm{~ms}$. In view of the fact that a reduction in the incidence of AF associated with amiodarone prophylaxis was not associated with a significant reduction in duration of hospital stay, but was associated with an increased risk of hypotension, bradycardia, and QTc interval prolongation, surgeons and clinicians caring for patients undergoing esophagectomy must weigh the individualized risks versus benefits of amiodarone prophylaxis of AF in this population. In particular, the risks may outweigh the benefits in specific patients, such as those with lower preoperative blood pressures; preoperative bradycardia; preoperative QTc intervals $>450 \mathrm{~ms}$; and those with risk factors for QTc interval prolongation such as hypokalemia, hypomagnesemia, heart failure, and taking other drugs known to prolong the QTc interval.

In this real-world practice study, amiodarone was used for the treatment of postesophagectomy AF that occurred in both the control group and the amiodarone prophylaxis 


\section{Hypothesis}

Prophylactic intravenous amiodarone reduces the incidence of AF following esophagectomy

\section{Methods}

Retrospective Cohort Study

1:1 Propensity Score-Matched
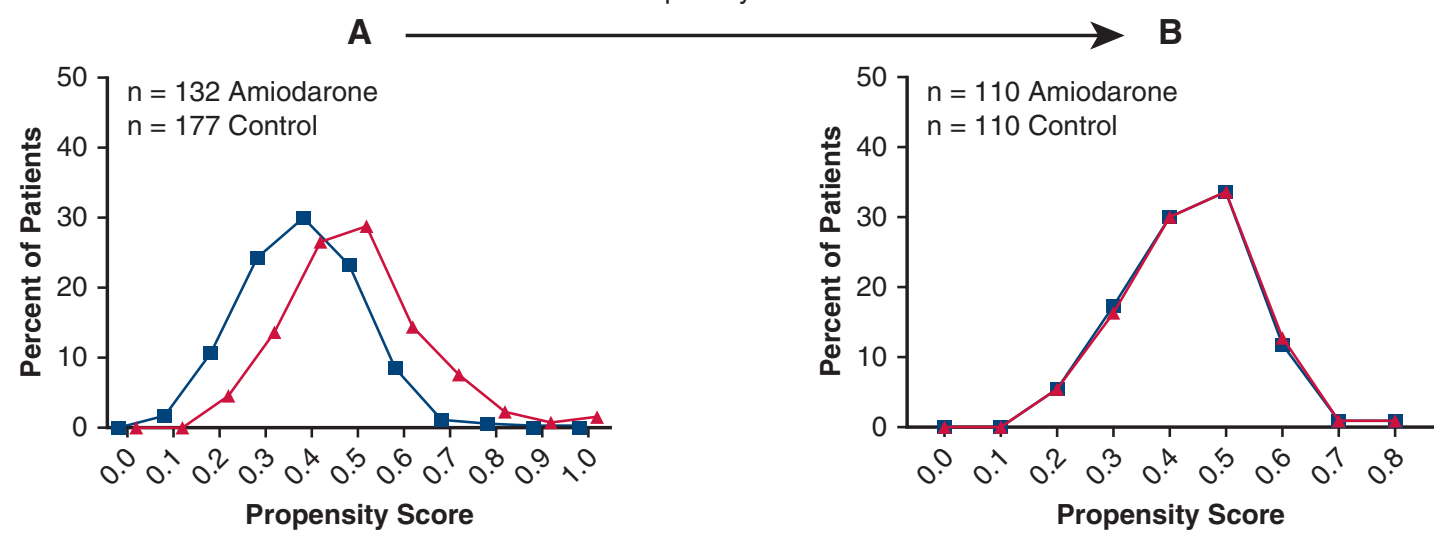

Results
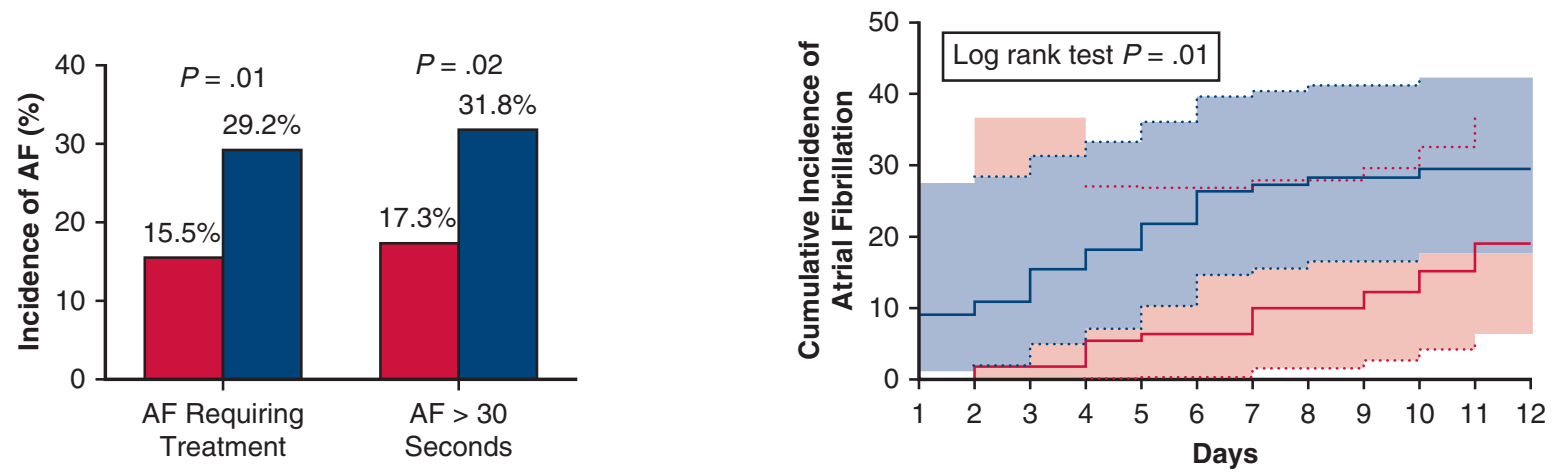

Subjects at Risk

$\begin{array}{llllllllllllll}\text { Control } & n=110 & 100 & 98 & 93 & 91 & 86 & 81 & 80 & 79 & 79 & 78 & 78 & 78\end{array}$

Amiodarone $\mathrm{n}=110 \quad 11010810810410310399 \quad 99 \quad 97 \quad 95 \quad 93 \quad 93$

\begin{tabular}{|l|l|l|l|}
\hline & Amiodarone & Control & $P$ \\
\hline Hypotension & $42.7 \%$ & $21.8 \%$ & .001 \\
\hline Bradycardia & $8.2 \%$ & $0 \%$ & .002 \\
\hline QTc Interval $>500 \mathrm{~ms}$ & $10.9 \%$ & $0 \%$ & $<.0001$ \\
\hline
\end{tabular}

\section{Conclusion}

Amiodarone prophylaxis is associated with:

- Reduced incidence of post-esophagectomy AF

- No difference post-operative LOS

- Increased incidence of: hypotension, bradycardia, QTc prolongation

FIGURE 3. A, Comparison of amiodarone and control groups before propensity score matching ( $\mathrm{n}=132$ amiodarone and $\mathrm{n}=177 \mathrm{control})$. B, Comparison of amiodarone and control groups after propensity score matching $(\mathrm{n}=110$ amiodarone and $\mathrm{n}=110$ control). Red denotes amiodarone, blue denotes control. Confidence limits for amiodarone (red) and control group (blue) indicated by shading. AF, Atrial fibrillation; $Q T c$, corrected QT interval; LOS, length of stay. 
group. Therefore, some patients received a cumulative amiodarone dose higher $(>4200 \mathrm{mg})$ than that previously shown to be safe and effective for prevention of postesophagectomy $\mathrm{AF}^{6}{ }^{6}$ and higher than the recommended prophylaxis dose. ${ }^{17}$ The incidence of amiodarone-associated hypotension requiring treatment and bradycardia in patients who received $>4200 \mathrm{mg}$ was significantly higher than in those patients who received $\leq 4200 \mathrm{mg}$. In addition, the incidence of QTc interval $>500 \mathrm{~ms}$ was significantly higher in patients who received amiodarone $>4200 \mathrm{mg}$ than in those who received $\leq 4200 \mathrm{mg}$; more than one-third of patients who received higher doses developed QTc interval $>500 \mathrm{~ms}$, increasing the risk of proarrhythmia.

The incidence of ARDS was not significantly higher in the high-dose amiodarone group; however, our sample size may not have been sufficiently large to detect a significant difference. ARDS associated with intravenous amiodarone has previously been reported in patients undergoing pneumonectomy, with an incidence as high as $27 \% .{ }^{29}$ In postpneumonectomy patients, ARDS was associated with cumulative intravenous amiodarone doses ranging from 2150 to $3750 \mathrm{mg}$ over 3 days. ${ }^{29}$ Patients undergoing esophagectomy are at risk for postoperative pulmonary complications, including pneumonia and ARDS, which may occur in $10 \%$ to $40 \%$ of patients. ${ }^{30}$ In our previous randomized study in which intravenous amiodarone was shown to reduce the incidence of postesophagectomy AF, there was no significant difference in the incidence of pulmonary complications between the amiodarone and control groups; however, only 40 patients received amiodarone. ${ }^{6}$

In our present study, there was no significant difference in the proportion of patients in sinus rhythm at 24 hours or in those who were discharged in AF between patients who received amiodarone for treatment of $\mathrm{AF}$ compared with those who received other treatments. However, the incidence of adverse effects, including hypotension requiring treatment, bradycardia, and QTc interval $>500 \mathrm{~ms}$ is substantially higher in patients who undergo amiodarone prophylaxis, subsequently develop postesophagectomy AF, and who then continue to receive amiodarone for AF treatment. Therefore, in patients who receive amiodarone for $\mathrm{AF}$ prophylaxis but who subsequently develop postesophagectomy $\mathrm{AF}$, the risks of managing the $\mathrm{AF}$ with continued amiodarone therapy may outweigh the benefits, and alternative AF therapies should be considered. Further study is recommended to address the safety of intravenous amiodarone for treatment of postesophagectomy $\mathrm{AF}$ in those patients who had received the drug for $\mathrm{AF}$ prophylaxis.

Limitations of this study include the fact that, due to imprecise and inconsistent recording of time of admission and discharge from the ICU, the duration of ICU stay in the amiodarone and control groups could not be determined. Incomplete data capture is a possibility in this type of study.
Propensity-score matching is associated with limitations. If the propensity score model is incorrect, then the fitted propensity scores could be biased. However, our propensity score fits were very good, and led to well-matched groups with standardized mean differences $<0.2 \%$. Although our propensity score-matching resulted in a well-matched control group, residual confounding cannot be entirely discounted. Because the decision to select patients for amiodarone prophyaxis was made by individual surgeons, the possibility of residual confounding by indication exists. Our study may also be underpowered to detect significant differences in postoperative duration of hospital stay.

\section{CONCLUSIONS}

Intravenous amiodarone is associated with a reduction in the incidence of AF after esophagectomy. However, amiodarone prophylaxis is not associated with a significant reduction in duration of postoperative hospital stay, and is associated with a risk of hypotension, bradycardia, and QTc interval prolongation (Figure 3). Consequently, surgeons and other clinicians should carefully weigh the risks versus benefits of amiodarone prophylaxis of $\mathrm{AF}$ in patients undergoing esophagectomy.

\section{Conflict of Interest Statement}

Authors have nothing to disclose with regard to commercial support.

\section{References}

1. Konno O, Tezuka T, Muto A, Hoshino Y, Kogure M, Koyama S, et al. [Postoperative arrhythmia after operation of esophageal cancer]. Nippon Kyobu Geke Gakkai Zasshi. 1993;41:45-51.

2. Amar D, Burt ME, Bains MS, Leung DH. Symptomatic tachydysrhythmias after esophagectomy: incidence and outcome measures. Ann Thorac Surg. 1996;61: 1506-9.

3. Murthy SC, Law S, Whooley BP, Alexandrou A, Chu KM, Wong J. Atrial fibrillation after esophagectomy is a marker for postoperative morbidity and mortality. J Thorac Cardiovasc Surg. 2003;126:1162-7.

4. Vaporciyan AA, Correa AM, Rice DC, Roth JA, Smythe WR, Swisher SG, et al. Risk factors associated with atrial fibrillation after noncardiac thoracic surgery: analysis of 2588 patients. J Thorac Cardiovasc Surg. 2004;127:779-86.

5. Stippel DL, Taylan C, Schröder W, Beckurts KT, Hölscher AH. Supraventricular tachyarrhythmia as early indicator of a complicated course after esophagectomy. Dis Esophagus. 2005;18:267-73.

6. Tisdale JE, Wroblewski HA, Wall DS, Rieger KM, Hammoud ZT, Young JV, et al. A randomized, controlled study of amiodarone for prevention of atrial fibrillation after transthoracic esophagectomy. J Thorac Cardiovasc Surg. 2010;140: 45-51.

7. Stawicki SP, Prosciak MP, Gerlach AT, Bloomston M, Davido HT, Lindsey DE, et al. Atrial fibrillation after esophagectomy: an indicator of postoperative morbidity. Gen Thorac Cardiovasc Surg. 2011;59:399-405.

8. Raman T, Roistacher N, Liu J, Zhang H, Shi W, Thaler HT, et al. Preoperative left atrial dysfunction and risk of postoperative atrial fibrillation complicating thoracic surgery. J Thorac Cardiovasc Surg. 2012;143:482-7.

9. Rao VP, Addae-Boateng E, Barua A, Martin-Ucar AE, Duffy JP. Age and neoadjuvant chemotherapy increase the risk of atrial fibrillation following oesophagectomy. Eur J Cardiothorac Surg. 2012;42:438-43.

10. Amar D, Zhang H, Shi W, Downey RJ, Bains MS, Park BJ, et al. Brain natriuretic peptide and risk of atrial fibrillation after thoracic surgery. J Thorac Cardiovasc Surg. 2012;144:1249-53. 
11. Ojima T, Iwahashi M, Nakamori M, Nakamura M, Katsuda M, Iida T, et al. Atrial fibrillation after esophageal cancer surgery: an analysis of 207 consecutive patients. Surg Today. 2014;44:839-47.

12. Lohani KR, Nandipati KC, Rollins SE, Fetten K, Lee TH, Pallati PK, et al. Transthoracic approach is associated with increased incidence of atrial fibrillation after esophageal resection. Surg Endosc. 2015;29:2039-45.

13. McCormack O, Zaborowski A, King S, Healy L, Daly C, O'Farrell N, et al. Newonset atrial fibrillation post-surgery for esophageal and junctional cancer: incidence, management, and impact on short- and long-term outcomes. Ann Surg. 2014;260:772-8.

14. Day RW, Jaroszewski D, Chang YH, Ross HJ, Paripati H, Ashman JB, et al. Incidence and impact of postoperative atrial fibrillation after minimally invasive esophagectomy. Dis Esophagus. 2016;29:583-8.

15. Chin JH, Moon YJ, Jo JY, Han YA, Kim HR, Lee EH, et al. Association between postoperatively developed atrial fibrillation and long-term mortality after esophagectomy in esophageal cancer patients: an observational study. PLoS One. 2016; 11:e0154931.

16. Tisdale JE, Wroblewski HA, Kesler KA. Prophylaxis of atrial fibrillation after noncardiac thoracic surgery. Semin Thorac Cardiovasc Surg. 2010;22: 310-20.

17. Fernando HC, Jaklitsch MT, Walsh GL, Tisdale JE, Bridges CD, Mitchell JD, et al. The Society of Thoracic Surgeons practice guideline on the prophylaxis and management of atrial fibrillation associated with general thoracic surgery: executive summary. Ann Thorac Surg. 2011;92:1144-52.

18. Frendl G, Sodickson AC, Chung MK, Waldo AL, Gersh BJ, Tisdale JE, et al. 2014 AATS guidelines for the prevention and management of perioperative atrial fibrillation and flutter for thoracic surgical procedures. J Thorac Cardiovasc Surg. 2014;148:772-91.

19. Guarnieri T, Nolan S, Gottlieb SO, Dudek A, Lowry DR. Intravenous amiodarone for the prevention of atrial fibrillation after open heart surgery: the Amiodarone Reduction in Coronary Heart (ARCH) trial. J Am Coll Cardiol. 1999:34:343-7.

20. The ARDS Definition Task Force. Acute respiratory distress syndrome. The Berlin definition. JAMA. 2012;307:2526-33.
21. Charlson ME, Pompei P, Ales KL, MacKenzie CR. A new method of classifying prognostic comorbidity in longitudinal studies: development and validation. $J$ Chronic Dis. 1987;40:373-83.

22. Ma JY, Wang Y, Zhao YF, Wu Z, Liu LX, Kou YL, et al. Atrial fibrillation after surgery for esophageal carcinoma: clinical and prognostic significance. World J Gastroenterol. 2006;12:449-52.

23. Hahm TS, Lee JJ, Yang MK, Kim JA. Risk factors for an intraoperative arrhythmia during esophagectomy. Yonsei Med J. 2007;48:474-9.

24. Crystal E, Connolly SJ, Sleik K, Ginger TJ, Yusuf S. Interventions on prevention of postoperative atrial fibrillation in patients undergoing heart surgery: a metaanalysis. Circulation. 2002;106:75-80.

25. Mitchell LB, Exner DV, Wyse DG, Connolly CJ, Prystal GD, Bayes AJ, et al. Prophylactic oral amiodarone for the prevention of arrhythmias that begin early after revascularization, valve replacement, or repair. PAPABEAR: a randomized, controlled trial. JAMA. 2005;294:3093-100.

26. Tisdale JE, Wroblewski HA, Wall DS, Rieger KM, Hammoud ZT, Young JV, et al. A randomized trial evaluating amiodarone for prevention of atrial fibrillation after pulmonary resection. Ann Thorac Surg. 2009;88:886-95.

27. Riber LP, Christensen TD, Pilegaard HK. Amiodarone is a cost-neutral way of preventing atrial fibrillation after surgery for lung cancer. Eur J Cardiothorac Surg. 2014;45:120-5.

28. Trinkley KE, Page RL II, Lien H, Yamanouye K, Tisdale JE. QT interval prolongation and the risk of torsades de pointes: essentials for clinicians. Curr Med Res Opin. 2013;29:1719-26

29. Van Mieghem W, Coolen L, Malysse I, Lacquet LM, Denefe JD, Demedts MGP. Amiodarone and the development of ARDS after lung surgery. Chest. 1994;105: 1642-5.

30. Briez N, Piessen G, Torres F, Lebuffe G, Triboulet J-P, Mariette C. Effects of hybrid minimally invasive oesophagectomy on major postoperative pulmonary complications. Br J Surg. 2012;99:1547-53.

Key Words: amiodarone, atrial fibrillation, esophagectomy, prophylaxis, propensity score 


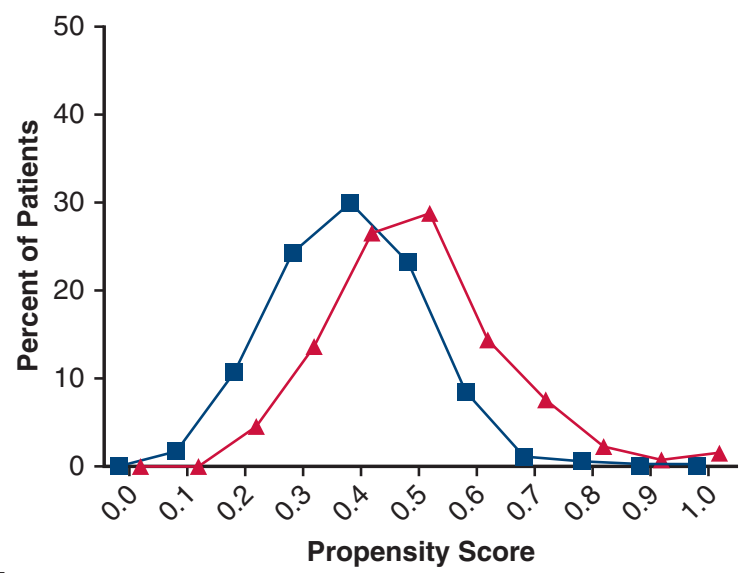

A

Propensity Score

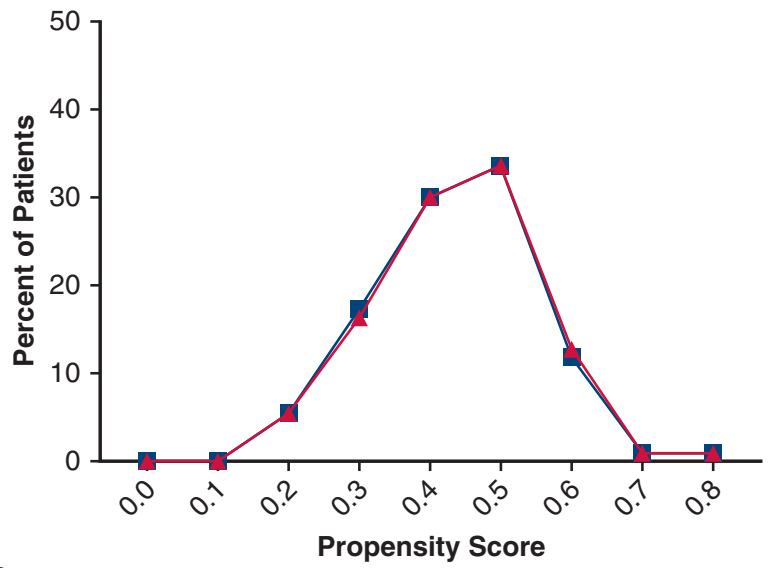

B

FIGURE E1. Propensity score histograms. A, Comparison of amiodarone (red) and control (blue) groups before propensity score matching. B, Comparison of amiodarone (red) and control (blue) groups after propensity score matching. 